\title{
Controlled crystallization in Ge-(Sb/Ga)-(S/Se)-MX glasses for infrared applications
}

\author{
Laurent CALVEZ, Mathieu ROZÉ, Yannick LEDEMI, Hong-Li MA, Jacques LUCAS, Mathieu ALLIX, **** \\ Guy MATZEN ${ }^{* * * *}$ and Xiang-Hua ZHANG
}

Equipe Verres et Céramiques, UMR-CNRS 6226, Sciences chimiques de Rennes, Université de Rennes1, 35042 Rennes Cedex, France ${ }^{*}$ CNRS, UPR3079 CEMHTI, ID avenue de la Recherche Scientifique, 45071 Orléans Cedex2, France

**Université d'Orléans, Avenue du Parc Floral, BP 6749, 45067 Orléans Cedex 2, France

In this paper, the last glass-ceramics recently made from chalco-halide glasses is presented. Various glass-ceramics were obtained from compositions belonging to different systems such as Ge-(Sb/Ga)-(S/Se)-MX (MX: alkali halide). XRD experiments and SEM observations were performed to determine the crystallization mechanism in these chalcogenide glasses. While alkali halide such as $\mathrm{CsCl}$ is rejected from the glassy network in antimony based glasses leading to its crystallization, some gallium based glasses present a quasi-arranged structure which tends to reach a higher stability by crystallizing as $\mathbf{G a}_{4} \mathrm{GeSe}_{8}$ or $\mathrm{Ga}_{2} \mathrm{Se}_{3}$. Thus, the amount of alkali halides introduced in antimony based glasses limits the crystallization rate to $20 \%$ of the glassy matrix. Furthermore, the crystallization of gallium based phases having a refractive index close to the matrix one lowers the scatterings permitting to keep an excellent infrared transmittance with a crystallized proportion of about $40 \%$.

(C)2008 The Ceramic Society of Japan. All rights reserved.

Key-words : Chalco-halide glasses, Glass-ceramics, Mechanical properties, Infrared, Optical properties

[Received June 5, 2008; Accepted September 11, 2008]

\section{Introduction}

While many papers report the synthesis of alumino-silicate or oxy-fluoride glass-ceramics, few deal with chalcogenide glassceramics. Since few years, investigations have demonstrated that chalcogenide glass-ceramics present interesting characteristics for active optical applications as rare earth doping or non linear effects $^{1-3)}$ and for passive optical applications. ${ }^{4)}$ The wide range of transmittance of chalcogenide glasses contrasts with their weak mechanical properties such as low hardness and low resistance to thermal shocks. Melchosky et al. reported the first chalcogenide glass-ceramic from $\mathrm{Ge}-\mathrm{As}-\mathrm{Pb}-\mathrm{Se}$ system transparent in the $8-13 \mu \mathrm{m}$ region with improved mechanical properties. ${ }^{5)}$ Then Cheng obtained glass-ceramics with crystals below $1 \mu \mathrm{m}$ size from the As-Ge-Se-Sn system using $\mathrm{ZrSe}{ }_{2}$ as a nucleating agent. ${ }^{6}$ Even if numerous thermodynamical studies of crystallization on chalcogenide glasses were performed, the crystallization process to generate nanoparticles inside the glassy matrix is still difficult to control. ${ }^{7-9)}$ Whereas both homogeneous and heterogeneous nucleations with addition of nucleating agent were used in order to generate submicron crystals; all results lead to glass-ceramics with strongly deteriorated infrared transmission. However, these first results indicate a strong increase of mechanical properties such as improved hardness and toughness. Also, Yang et al. have recently obtained controlled glass-ceramics in the $\mathrm{GeSe}_{2}-\mathrm{As}_{2} \mathrm{Se}_{3}-\mathrm{PbSe}$ system which present suitable transmittance in the infrared region and improved mechanical properties. ${ }^{10)}$

Tver'yanovich et al. have demonstrated that high quantity of ionic compounds such as $\mathrm{CsCl}$ could be dissolved in a covalent matrix like chalogenide glasses. ${ }^{11)}$ Our first work was focused on the research of a glass composition containing high amount of dissolved alkali halide, close to compositions containing an over- saturated solution of alkali halide leading to its whole crystallization during quenching. Thus, glasses with high alkali halide were heat treated to generate submicron crystals in order to improve mechanical properties without modifying the infrared transmission.

\section{Experimental details}

\subsection{Glass synthesis}

Glasses are prepared by melting, in a rocking furnace, pure raw materials (Ge, Sb, Ga, Se, S: $99.999 \%$ and alkali halide $99.9 \%)$ contained in a sealed silica ampoule under vacuum $\left(10^{-3}\right.$ $\mathrm{Pa}$. The tube is heated up to $750^{\circ} \mathrm{C}-850^{\circ} \mathrm{C}$ with a rate of $2-3^{\circ} \mathrm{C} /$ min depending on the glass composition. A dwell of $12 \mathrm{~h}$ is carried out to facilitate the glass homogenization. Then, the melt is quenched in water at room temperature, annealed at $T_{\mathrm{g}}-10^{\circ} \mathrm{C}$ for $4 \mathrm{~h}$ and finally slowly cooled down to room temperature in order to minimize inner constraints. Glass rods were cut into slices of $2 \mathrm{~mm}$ thick and were polished to measure optical and mechanical properties and to perform ceramisation experiments.

\subsection{Samples characterization}

To determine the glass forming region of each studied system, UV-Visible and IR spectrometers were used. The transmission range was characterized with a double beam spectrophotometer (CARY5_Varian) in the short wavelengths range. A BRUKER Vector 22 spectrophotometer was used for the mid and far infrared spectra. The glass refractive index was estimated from the transmission curve of each glass. A differential scanning calorimeter (DSC2910 TA Instruments) was used with a heating rate of $10^{\circ} \mathrm{C} / \mathrm{min}$ to determine the characteristic temperatures of glasses and glass-ceramics such as glass transition temperature $\left(T_{\mathrm{g}}\right)$ and onset crystallization temperature $\left(T_{x}\right)$. Crystals in the glassy matrix were observed by Scanning Electronic 
Microscope (SEM), in a crack created on the glass surface. Previously, a thin gold-palladium film was deposited on glassceramics samples because of their electrically insulating character.

X-ray diffraction pattern of polished slices were collected on a Bruker-AXS D8 Advance diffractometer to determine crystalline phases generated during heat treatment. Experiments performed on glass powder presented the same results obtained with bulk, indicating that the crystallization takes place inside the glassy matrix.

Hardness $\left(H_{\mathrm{v}}\right)$ and toughness $\left(K_{\mathrm{c}}\right)$ were determined by using a Vickers micro indenter with a load of $100 \mathrm{~g}$ for $5 \mathrm{~s}$.

\section{Results}

\subsection{Composition}

The first way explored to facilitate a controlled crystallization was to incorporate ionic compounds in a covalent glassy matrix. In this work we have introduced $\mathrm{CsCl}$ in two families of glasses: glasses containing antimony in the first one and glasses containing gallium in the second one. Firstly, alkali halides have been added in $\mathrm{Ge}-\mathrm{Sb}-\mathrm{S}$ base glasses. After a systematic study, the $62.5 \mathrm{GeS}_{2} \cdot 12.5 \mathrm{Sb}_{2} \mathrm{~S}_{3} \cdot 25 \mathrm{CsCl}$ glass composition was chosen to generate nanocrystalline particles inside the glassy matrix as its crystallization is reproducibly controllable. This glass has a $T_{\mathrm{g}}$ of $262^{\circ} \mathrm{C}$ and a $T_{x}$ of about $380^{\circ} \mathrm{C}$ and is transparent from $0.55 \mu \mathrm{m}$ to $11.5 \mu \mathrm{m}$. $^{12}$

Then, in order to fully take advantages of the third atmospheric window between 8 and $12 \mu \mathrm{m}$, sulfur was replaced by selenium. Glasses belonging to the $\mathrm{Ge}-\mathrm{Sb}-\mathrm{Se}-\mathrm{CsCl}$ system present an extended transmission from $0.8 \mu \mathrm{m}$ up to $16 \mu \mathrm{m}$. Furthermore, different alkali halides were incorporated to study the influence of the ionic strength on the glass forming ability. ${ }^{13)}$ The main observation was the decrease of the glass forming region with halides of higher electronegativity or with smaller cations. As a result, following the way of thinking that alkali halide will crystallize after being rejected from the glassy network; the crystallized proportion would be lower with chlorine base alkali than with iodine. The choice of glass compositions in the $\mathrm{GeSe}_{2}-\mathrm{Sb}_{2} \mathrm{Se}_{3}-\mathrm{CsCl}$ system was limited because of the small glass forming region not exceeding $10 \% \mathrm{~mol}$. of $\mathrm{CsCl}$. The $73 \mathrm{GeSe}_{2} \cdot 20 \mathrm{Sb}_{2} \mathrm{Se}_{3} \cdot 7 \mathrm{CsCl}$ glass has shown a tendency to crystallize homogeneously. This dark glass presents a $T_{\mathrm{g}}$ of $254^{\circ} \mathrm{C}$ and no crystallization peak below $400^{\circ} \mathrm{C}$.

Gallium is known to permit the chalcogenide glasses bleaching and also the incorporation of high amount of rare earth. To obtain a wider transparency in the visible range, the antimony was substituted by gallium in the Ge-Sb-Se/S-MX (MX: alkali halide) systems. As a result, selenium based glasses presenting a pale red color and wide transmittance overspreading the second and third atmospheric windows were synthesized. ${ }^{14)-16)}$ Also, some sulfur based glasses containing more than $40 \%$ of $\mathrm{CsCl}$ are totally transparent in the visible range up to $11.5 \mu \mathrm{m} .{ }^{17)}$

To perform ceramisation experiments in order to improve mechanical properties, the following two glass compositions were chosen: $63 \mathrm{GeSe}_{2} \cdot 27 \mathrm{Ga}_{2} \mathrm{Se}_{3} \cdot 10 \mathrm{CsCl}$ and $65 \mathrm{GeS}_{2} \cdot 25 \mathrm{Ga}_{2} \mathrm{~S}_{3}$. $10 \mathrm{CsCl}$. The first cited glass present a $T_{\mathrm{g}}$ of $357^{\circ} \mathrm{C}$ and a $T_{x}$ of $458^{\circ} \mathrm{C}$. DSC measurement performed on the second one reveals a glass transition temperature $T_{\mathrm{g}}=405^{\circ} \mathrm{C}$, an onset crystallization temperature for the first peak $T_{x 1}=504^{\circ} \mathrm{C}$ and $T_{x 2}=545^{\circ} \mathrm{C}$ for the second one.

The selenium based glass is slightly transparent in the visible up to $16 \mu \mathrm{m}$ while the $65 \mathrm{GeS}_{2} \cdot 25 \mathrm{Ga}_{2} \mathrm{~S}_{3} \cdot 10 \mathrm{CsCl}$ glass, presenting a yellowish color, is transparent in the visible range up to 11.5 $\mu \mathrm{m}$.

Afterwards, ceramisation tests were performed on a $\mathrm{Ge}-\mathrm{Ga}-\mathrm{Se}$ glass without addition of alkali halide in order to understand the role played by alkali halide in the previous glasses. The $80 \mathrm{GeSe}_{2} \cdot 20 \mathrm{Ga}_{2} \mathrm{Se}_{3}$, which has a $T_{\mathrm{g}}$ of $370^{\circ} \mathrm{C}$ and a $T_{x}$ of $460^{\circ} \mathrm{C}$ present a tendency to homogeneously generate nanocrystals inside the glassy matrix.

To summary, five compositions were compared in this investigation: $62.5 \mathrm{GeS}_{2} \cdot 12.5 \mathrm{Sb}_{2} \mathrm{~S}_{3} \cdot 25 \mathrm{CsCl}(\mathrm{G} 1),{ }^{73} \mathrm{GeSe}_{2} \cdot 20 \mathrm{Sb}_{2} \mathrm{Se}_{3}$. $7 \mathrm{CsCl}(\mathrm{G} 2), 63 \mathrm{GeSe}_{2} \cdot 27 \mathrm{Ga}_{2} \mathrm{Se}_{3} \cdot 10 \mathrm{CsCl}(\mathrm{G} 3), 65 \mathrm{GeS}_{2} \cdot 25 \mathrm{Ga}_{2} \mathrm{~S}_{3}$. $10 \mathrm{CsCl}(\mathrm{G} 4)$ and $80 \mathrm{GeSe}_{2} \cdot 20 \mathrm{Ga}_{2} \mathrm{Se}_{3}(\mathrm{G} 5)$.

\subsection{Heat treatment}

The heat treatment time and temperature were specifically determined for each glass composition. In fact, two techniques can be used to generate a controlled crystallization in chalcogenide glasses. First, a two-step technique consisting in a nucleation step followed by a growth step at higher temperature should be used for glasses presenting a relatively high stability against crystallization. Usually one step can be enough for glasses having a difference between the glass transition temperature and the crystallization temperature less than $100^{\circ} \mathrm{C}$.

Accordingly, G1, G2 were heat treated at $290^{\circ} \mathrm{C}, 30^{\circ} \mathrm{C}$ over $T_{\mathrm{g}}$ for different times while the $\mathrm{G} 4$ glass was heat treated $20^{\circ} \mathrm{C}$ above $T_{\mathrm{g}}$ at $425^{\circ} \mathrm{C}$. The $\mathrm{G} 5$ glass presenting a faster crystallization was heat treated at $380^{\circ} \mathrm{C}$ for different durations. Despite its low difference between $T_{\mathrm{g}}$ and $T_{x}$ and in order to avoid an uncontrollable growth of crystals, a two step technique was used for the $\mathrm{G} 3$ glass by nucleating $2 \mathrm{~h}$ at $387^{\circ} \mathrm{C}$ and then $30 \mathrm{~min}$ at $410^{\circ} \mathrm{C}$ to allow the crystal growth.

The microstructures of different glass-ceramics obtained by

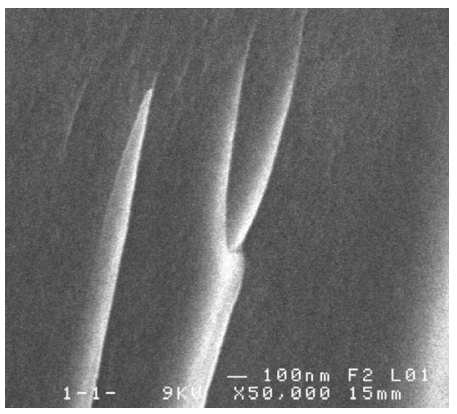

(a)

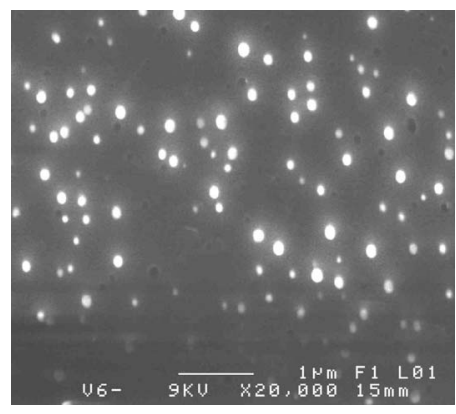

(b)

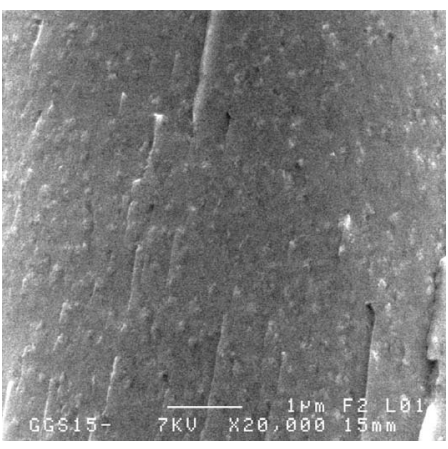

(c)

Fig. 1. Pictures captured by SEM of the G2 base glass (a), G2 at $290^{\circ} \mathrm{C} 30 \mathrm{~h}$ (b), G5 $12 \mathrm{~h}$ at $380^{\circ} \mathrm{C}$ (c). 


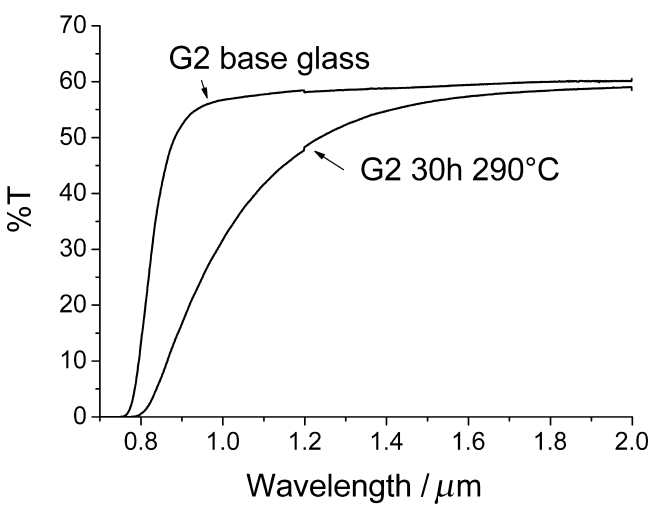

(a)

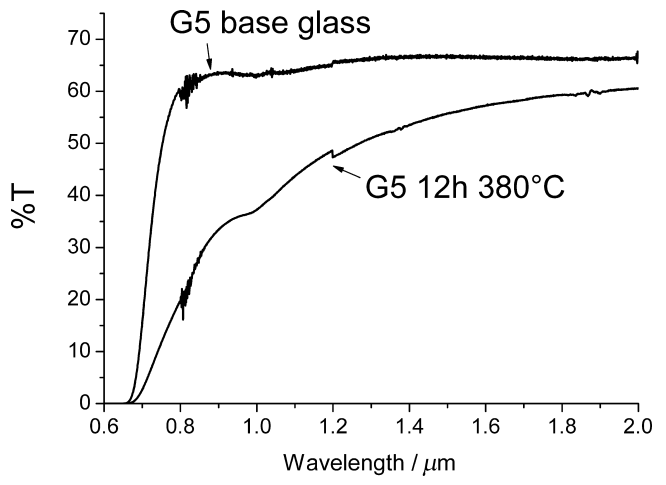

(b)

Fig. 2. Optical transmission spectra of G2 (a) and G5 glass-ceramic samples (b).

using SEM are presented in Fig. 1. It is clear that crystals are homogeneously distributed in all glassy matrixes.

The submicron particles generated in the antimony based glasses are spherical while particles belonging to glassy matrix containing gallium are not uniform and appear as an aggregate of numerous nanoparticles. Both types of crystals can be controlled under a size of $100 \mathrm{~nm}$ with appropriated heat treatment time. The crystallized part reached in the antimony based glassceramic is about $10 \%$ and about $20 \%$ for gallium based glassceramics.

Two transmission curves comparing sulfide based glassceramics or selenide glass-ceramics containing crystals of 100 $\mathrm{nm}$ size are presented in Fig. 2. It can be noticed that almost the same shift of transmission towards longer wavelength is observed while gallium based glass-ceramics present a twice higher rate of crystallization meaning that scatterings induced by crystals generated in glasses with antimony are more important.

\subsection{Structure analysis}

As it is well known in silicate glasses, the halides lead to a decrease of the glass network reticulation by forming non bridging atoms. The same phenomenon occurs in chalco-halide glasses. As a consequence, the chalcogen elements like $\mathrm{S}$ or Se present a partial negative charge which ensures the ionic bond with alkali atoms which can freely move into the glass network. Thus, the progressive increase of alkali halide amount conduces to the deterioration of mechanical properties, and also to a shift of the beginning of transmission toward shorter wavelengths. ${ }^{12), 13)}$

$\mathrm{X}$-rays analysis has demonstrated that in sulfur and in selenium based glasses containing $\mathrm{Sb}$ and $\mathrm{CsCl}$, the first phase which appears indicates the presence of cesium. ${ }^{12)}$ In fact, a cubic phase close to $\mathrm{CsCl}$ crystallizes in the $\mathrm{G} 1$ glass after $7 \mathrm{~h}$ at $290^{\circ} \mathrm{C}$, and the same phenomenon is observable as well in the $\mathrm{G} 2$ glass heat treated at $290^{\circ} \mathrm{C}$ for $30 \mathrm{~h}$. Contrarily to glasses where $\mathrm{CsCl}$ seems to be rejected of the glass network to reach a higher stability, glasses containing gallium show a different process of crystallization as crystallized phases containing gallium appear first.

As previously demonstrated, the $\mathrm{Ga}_{2} \mathrm{Se}_{3}$ phase grows in the $\mathrm{G} 3$ glassy matrix after $2 \mathrm{~h}$ at $387^{\circ} \mathrm{C}$ and then $30 \mathrm{~min}$ at $410^{\circ} \mathrm{C}$. In this last case, the whole glass network crystallizes under nanoparticles which quickly aggregate, forming crystals of about 100 nm size. ${ }^{14)}$

Observing these results, one can suppose that gallium base

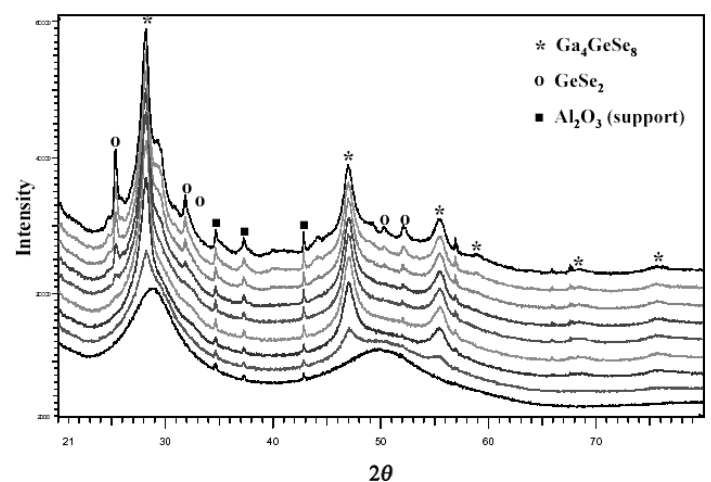

Fig. 3. XRD patterns run every $5 \mathrm{~h}$ on the $80 \mathrm{GeSe}_{2} \cdot 20 \mathrm{Ga}_{2} \mathrm{Se}_{3}$ base glass heat treated at $380^{\circ} \mathrm{C}$ from $t=0 \mathrm{~h}$ to $t=40 \mathrm{~h}$ at $380^{\circ} \mathrm{C}$.

glasses which homogeneously and reproducibly crystallizes with appropriated heat treatment time and temperature, present since the beginning a slight arranged structure where Ga surrounded by Se atoms seems to play the role of nucleating agent.

This assumption is also put forward by heat treating the $80 \mathrm{GeSe}_{2} \cdot 20 \mathrm{Ga}_{2} \mathrm{Se}_{3}$ base glass at $380^{\circ} \mathrm{C}$ for different time leading to controllable and reproducible glass-ceramics. The crystallization of the $\mathrm{Ga}_{4} \mathrm{GeSe}_{8}$ phase for short heat treatment time has been determined by X-ray analysis (Fig. 3). Considering this parameter, one can observe that the remaining glassy matrix tends to $\mathrm{GeSe}_{4 / 2}$. X-ray analysis made on glass ceramics after long heat treatment show the apparition of crystalline $\mathrm{GeSe}_{2}$ which corroborates the first assumption.

\subsection{Optical and mechanical properties}

It is well known that the generation of crystals in a glassy matrix induces scatterings depending on the size and the proportion of crystals as well as on the refractive index difference between the crystals and the glassy matrix. While a small proportion of about 10 to $20 \%$ of CsCl-like crystals induce a progressive opacity of the composite, the crystallized phases containing essentially gallium selenide can be as high as $40 \%$ to $60 \%$, keeping a wide maximal transmittance in the infrared region. This phenomenon can be explained by referring to Hendy's equation which shows the importance of having small crystals and/or a small difference between the glass refractive index $\mathrm{n}$ and that of the crystalline phase in order to minimize scatterings. ${ }^{18)}$ The crystallization of phases such as $\mathrm{Ga}_{4} \mathrm{GeSe}_{8}$ or 
$\mathrm{Ga}_{2} \mathrm{Se}_{3}(n=2.4)^{19)}$ instead of $\mathrm{CsCl}(n=1.6)^{20)}$ in a selenide glass having a refractive index of about 2.5 induces few modification of the transmittance even in the short wavelength. In the same way, the crystallization of $\mathrm{Ga}_{2} \mathrm{~S}_{3}$ ( $\mathrm{n}$ is estimated around 2.0) phases in sulfide glasses with $10 \%$ mol. of $\mathrm{CsCl}$ having a refractive index of 2.1 induces lower scatterings than crystalline phases containing $\mathrm{CsCl}$.

Furthermore, while the toughness has doubled from 0.227 to $0.425 \mathrm{MPa} \cdot \mathrm{m}^{1 / 2}$ in the glass-ceramics made from the G3 glass, ${ }^{14)}$ the crystallization of alkali halide phases usually does not affect significantly the mechanical properties of the composite. ${ }^{21)}$ In fact, the crystallization of alkali halide phases does not compensate the decrease of mechanical properties when introducing increasing amount of alkali halides in the base glass.

This work offers different possibilities to orient new investigations. For example, the crystallization of hygroscopic materials as alkali halide which easily dissolved in water could be used to obtain porous composite whereas glass-ceramics with phases containing gallium will be used as materials with enhanced mechanical properties such as Young's modulus, hardness and toughness. Furthermore, the possibility to know what phase crystallizes will permit to modify the glass refractive index by adjusting the glass composition with more or less alkali halide.

\section{Conclusion}

In this paper, the importance to optimize the base glass composition for ceramization experiments has been demonstrated. In fact, while antimony based glasses containing alkali halides lead to the crystallization of alkali halide-like phases, gallium based glasses conduce to gallium selenide crystalline phase. Consequently, the field of applications of obtained glass-ceramics would differ according to the base glass composition. Furthermore, to minimize scatterings in order to keep a wide range of transparency, small crystals having a small difference of refractive index with the glassy matrix must be generated. Also, a high proportion of crystals with selected properties must be obtained to improve significantly the glass-ceramic mechanical properties.

Acknowledgement This work was supported by the French Délégation Générale pour l'Armement (DGA).

\section{References}

1) V. Seznec, H. L. Ma, H. H. Zhang, V. Nazabal, J.-L. Adam, X. S. Qiao and X. P. Fan, Opt. Mater., 29, 371 (2006).

2) G. Dong, H. Tao, X. Xiao, C. Lin, H. Guo and X. Zhao, Opt. Comm., 274[2], 466-470 (2007).

3) M. Guignard, V. Nazabal, X. H. Zhang, F. Smektala, A. Moreac, S. Pechev, H. Zeghlache, A. Kudlinski, G. Martinelli and Y. Quiquempois, Opt. Mater., 30[2], 338-345 (2007).

4) H. L. Ma, X. H. Zhang and J. Lucas. J. Non-Cryst. Solids, 317[3], 270-274 (2003).

5) J. J. Mecholsky Jun, C. T. Moynihan, P. B. Macedo and G. R. Srinivasan, J. Mater. Sci., 11[10], 1952-1960 (1976).

6) J. Cheng, G. Tilloca and J. Zarzycki, J. Mater. Sci., 16[9], 2531-2543 (1981).

7) S. M. Song, S. Y. Choi and Y. K. Lee, J. Non-Cryst. Solids, 217[1-2], 79-82 (1997).

8) E. Cernoskova, Z. G. Ivanova and V. Pamukchieva, Thermochim Acta., 316, 97 (1998).

9) J. Vasquez, P. L. Lopez-Alemany, P. Villares and R. JiménezGaray, J. Alloys Compd., 270, 179 (1998).

10) G. Yang, X. H. Zhang, J. Ren, Y. Yang, G. Chen, H. L. Ma and J. L. Adam, J. Am. Ceram. Soc., 90[5], 1500-1503 (2007).

11) Y.S. Tver'yanovich, E. G. Nedoshovenko, V. V. Aleksandrov, E. Y. Turkina, A. S. Tver'yanovich and I. A. Sokolov, Glass Phys. Chem., 22, 9 (1996).

12) X. H. Zhang, H. L. Ma and J. Lucas, J. Non-Cryst. Solids, 337, 130-135 (2004).

13) L. Calvez, H. L. Ma, J. Lucas and X. H. Zhang, J. Non-Cryst. Solids, 354[12-13], 1123-1127 (2008).

14) L. Calvez, H. L. Ma, J. Lucas and X. H. Zhang, Adv. Mater., 19[1], 129-132 (2006).

15) Z. Yang, G. Tang, L. Luo and W. Chen, J. Am. Ceram. Soc., 90[2], 667-669 (2007).

16) L. Calvez, P. Lucas, M. Roze, H. L. Ma, J. Lucas and X. H. Zhang, Appl. Phys. A, 89[1], 183-188 (2007).

17) Y. Ledemi, L. Calvez, M. Rozé, X. H. Zhang, B. Bureau, M. Poulain and Y. Messaddeq, J. Optoelectron. Adv. Mater., 9, 3751 (2007).

18) S. Hendy, Appl. Phys. Lett., 81[7], 1171 (2002).

19) M. A. Afifi, A. E. Bekheet, H. T. El-Shair and I. T. Zedan, Physica B: Condensed Matter., 325, 308-318 (2003).

20) P. G. Johannsen, G. Reib, U. Bohle, J. Magiera, R. Müller, H. Spiekermann and W. B. Holzapfel, Phys. Rev. B, 55, $6865-$ 6870 (1997).

21) S. Zhu, H. L. Ma, L. Calvez, X. H. Zhang, J. Lucas, J.-L. Adam, H. Shang and T. Rouxel, J. Non-Cryst. Solids, 353[13-15], 1298-1301 (2007). 